\title{
Identidade Cultural da América Latina: Conflitos Culturais Globais e Mediação Simbólica
}

\author{
Renato Seixas *
}

Resumo: A globalização contemporânea provoca fragmentação política, econômica, cultural e militar. A circulação caótica de elementos culturais gera conflitos entre culturas diferentes. Nesses processos dialéticos intervêm os agentes sociais de mediação dos significados culturais intertextuais, que fazem suas próprias narrativas dos aspectos multidimensionais da globalização atual e, assim, reorganizam num cosmos os significados multiculturais e polifônicos circulantes, para que sejam apreendidos e compreendidos pelos grupos sociais em que tais agentes atuam. A afirmação da identidade cultural da América Latina insere-se nesses processos.

Palavras-chave: Integração Cultural, Conflitos Culturais na Globalização.

Abstract: The contemporary stage of globalization causes political, economical, cultural and military fragmentation. The chaotic circulation of several cultural elements causes countless conflicts among different cultures. In these dialectic processes, it itefere social agents that make the mediation of the cultural meanings. Such agents produce their own narratives regarding the multidimensional aspects of the current globalization. Doing so, they reorganize in a cosmos the polyphonic and multicultural meanings that circulate, making them apprehensible and comprehensible to the social groups in which such agents act. The strengthening of the Latin American cultural identity cannot get away from these processes.

Keywords: Cultural Integration, Cultural Conflicts in the Globalization.

\footnotetext{
* Professor Doutor pelo PROLAM/USP e Professor da EACH - Escola de Artes, Ciências e Humanidades da USP. E-mail: renatoseixas@usp.br. Recebido em 15/04/08 e aceito em 12/05/08.
} 


\section{Introdução}

O fenômeno denominado globalização é multidimensional. A fase atual da globalização apresenta grande fracionamento dos poderes político, econômico e militar. $\mathrm{O}$ mesmo fenômeno ocorre com o poder cultural. Não se pode afirmar que a fragmentação cultural é conseqüência da pulverização dos demais poderes, nem que é a causa do fracionamento deles. Na verdade, existem processos dialéticos, interdependentes, inerentes à globalização contemporânea, que conduzem ao fracionamento de poderes e à relativização de culturas, umas em face das outras. Os conflitos culturais atuais são apenas um dos aspectos dessa dinâmica.

Nesse contexto, existiria uma identidade cultural genuinamente latinoamericana? Se essa identidade cultural existir, que critérios gerais ou particulares a caracterizariam? Como os elementos gerais de identificação da cultura ocidental dominante ou hegemônica (européia e norte-americana) coexistiriam com os elementos de identidade cultural da América Latina? Para tentar responder a estas indagações fundamentais é necessário certo grau de generalização a respeito da identidade cultural. Parti, então, de critérios mais amplos, generalizantes, suficientes para abranger o maior número possível de grupos sociais latino-americanos. Creio que somente assim se poderá falar de identidade cultural da ou na América Latina. Portanto, não são objetivos deste trabalho estudar as especificidades: (i) de culturas locais latino-americanas comparadas com outras; e (ii) culturais de certas classes sociais em contraste com outras classes dentro do mesmo grupamento social.

Nas décadas de 1980 e de 1990 o mundo perdeu a configuração bipolar de equilíbrio de poder que contrapunha a liderança dos Estados Unidos da América e a da União das Repúblicas Socialistas Soviéticas. A Nova Ordem Mundial tende a ser multipolar. É provável que ainda por algum tempo o equilíbrio de poder no mundo seja definido em função da existência de uma superpotência (atualmente os Estados Unidos da América), que dividirá sua influência com grandes potências mundiais. Potências regionais médias terão influência relativa nas suas respectivas regiōes. Por fim, potências subregionais terão alguma influência em seus espaços geopolíticos. Disto decorre fragmentação dos poderes político, econômico, cultural e militar entre os atores da sociedade internacional (DUPAS, 2005). Nesse contexto, torna- 
se cada vez mais complexo o sistema de divisão internacional do trabalho, atualmente baseado em intrincadas redes produtivas que integram diferentes regióes do globo (CHESNAYS, 1996). O crescente volume do comércio internacional provoca intensa circulação de bens e pessoas na arena mundial e isto, por sua vez, faz com que povos com culturas diferentes se relacionem mais uns com os outros. Por isto, os movimentos de auto-afirmação nacional, cultural e ou religiosa teráo importância cada vez maior. $O$ alinhamento ou distanciamento dos diferentes atores na sociedade internacional dependerá em grande parte de suas afinidades ou diversidades culturais (HARRISON, HUNTINGTON, 2002). Tornaram-se freqüentes as manifestaçóes de diferentes povos e naçóes em busca de auto-afirmação nacionalista, cultural e ou religiosa. Manifestaçôes como essas sempre existiram na história da humanidade, porém na fase atual da globalização apresentam aspectos específicos. Por outro lado, a fragmentação do poder político e econômico no mundo atual provoca a reformulação das identidades culturais, que passaram a ser instáveis, multicentradas e também muito fragmentadas (HALL, 2005). Os processos de integração política e econômica são indissociáveis dos processos de integração cultural e, por isto, é importante identificar e compreender suas correlaçóes, influências e confluências (CANCLINI, 2005). A História da humanidade está repleta de casos em que os poderes militar, econômico e político declinaram, mas o poder cultural não só subsistiu como também foi ampliado e aprofundado. Estados surgiram e desapareceram, mas muitas culturas transcenderam os Estados que as abrigavam. Como a distribuição de poder no mundo atual parece tender para a multipolaridade, a integração ou identificação cultural entre certos grupos humanos, Estados ou regióes está entre as dimensóes das relaçóes internacionais que irão influenciar as coalizóes ou as rivalidades entre eles (HUNTINGTON, 1997). É preciso investigar no contexto atual da globalização os processos pelos quais culturas diferentes podem tentar solucionar os conflitos culturais decorrentes de seu relacionamento (CANCLINI, 1991).

Este trabalho tem dois objetivos específicos: $1^{\circ}$ ) apresentar algumas das possíveis estruturas de formação e de reformulação das identidades culturais na fase atual da globalização; e $2^{\circ}$ ) analisar mais profundamente o processo dialético de mediação simbólica dos conflitos culturais inerentes à fase atual 
da globalização.. A identidade cultural da América Latina será examinada nesse contexto mais amplo.

Estão em curso diversos processos de integração regional latino-americana. Esses processos de integração têm dado ênfase à integração econômica (LAVINAS, CARLEIAL, NABUCO, 1994). A identidade cultural latinoamericana está pressuposta em algumas declaraçóes de princípios nos tratados de integração e há relativamente poucas iniciativas normativas para fomentar o intercâmbio cultural. Mas, até que ponto é legítimo pressupor uma identidade latino-americana? Existiria mesmo uma identidade cultural genuinamente latino-americana? Se pensarmos na América Latina como uma regiáo colonizada e explorada por europeus e norte-americanos durante os séculos; e se contrapusermos os interesses dos diferentes povos nativos das Américas Central e do Sul aos interesses dos europeus e norte-americanos, é claro que encontraremos uma identidade cultural latino-americana definida negativamente, no sentido anti-colonial e antiimperialista, ou seja, a identidade de povos que, contra sua vontade, foram colonizados, escravizados e explorados, e que não são europeus nem norte-americanos. Mas o passado colonial e a submissão aos impérios dominantes ou hegemônicos não são critérios suficientes para definir a identidade cultural de um povo, muito menos de dois continentes que têm certos aspectos muito heterogêneos (a América Central e a América do Sul). Que elementos, então, compóem a identidade cultural, ou mesmo civilizacional, dos povos latino-americanos? Adotado certo grau de generalização, pode-se falar numa cultura característica da América Latina, porém isto não significa que os diferentes povos latinoamericanos adotem sempre elementos uniformes de identificação cultural. As Américas Central e do Sul são geograficamente muito diferentes. A América Latina apresenta-se dividida em quatro sub-regióes, ou subsistemas: a) o subsistema amazônico; b) o subsistema andino; c) o subsistema platino (MELLO, 1996); e d) o subsistema da América Central e Caribe. As características geográficas de cada um desses subsistemas os tornam diferentes entre si. Essas diferenças geográficas influenciaram, em grande parte, o desenvolvimento de culturas e civilizações também distintas entre os grupos humanos que habitavam cada sub-região na fase pré-colonial. Esses povos adotaram diferentes formas de organização política, social, econômica 
e cultural. Por outro lado, muitos dos elementos que distinguiam as culturas pré-coloniais na América Latina foram destruídos ou foram obscurecidos pela sobreposição da cultura colonial européia a partir do início do século XVI (ROMANO, 1989). Disto resulta o discurso ideológico de que a identidade cultural da América Latina é latina, no sentido de que os povos colonizados teriam absorvido quase que completamente a cultura européia colonizadora; e americana, no sentido de que a América Central e a América do Sul passaram a ter uma única identidade cultural ocidental, na exata e restritiva medida em que os europeus e, mais tarde, os norte-americanos, tolerassem ter alguma identidade cultural com os povos da América Latina. É preciso desvelar a identidade cultural da América Latina, num grau mais elevado de generalização, e também a identidade cultural das sub-regióes latino-americanas. Os povos latino-americanos sabem que têm elementos culturais em comum, mas, de modo geral, os referenciais a partir dos quais organizam sua identidade cultural estão em profunda transformação. A América Latina está sob o impacto da fase atual da globalização e apresenta profunda miscigenação cultural, étnica, lingüística, religiosa. A globalização contemporânea exige o reconhecimento de novos elementos de identificaçáo cultural para revelar, em variados graus de generalização, como a identidade cultural da América Latina tem se reorganizado.

Este trabalho baseia-se em alguns autores emblemáticos que, em suas áreas de estudo, apresentam vertentes importantes para a compreensão da formação e da reformulação da identidade cultural no mundo contemporâneo. Samuel Huntington reflete sobre a identidade cultural e os conflitos culturais na fase atual da globalização. Por outro lado, a identidade cultural também se forma com arquetípicos, compostos por fatores biogenéticos, mitos e narrativas que fixam a origem de certa sociedade. Esses elementos, por serem universais, transitam no inconsciente individual ou coletivo e emergem nas diversas formas de narrativa do cotidiano. Trata-se da estrutura cultural arquetípica, que analisarei com base em Mircea Eliade. Pode-se analisar a identidade cultural com fundamento na estrutura cultural lidertípica, em que elementos culturais são apropriados pelos poderes dominantes no contexto de certa cultura a partir de critérios que correspondam aos interesses desses poderes e, a seguir, são disseminados pelos meios de comunicação social para 
serem reabsorvidos pela sociedade com significados também dominantes ou hegemônicos. As contribuiçôes de Néstor Canclini são muito úteis para compreender a estrutura cultural lidertípica. Também é possível analisar a identidade cultural por meio da miscigenação e interação multidimensional de elementos culturais de grupos diferentes. Tem-se aí a estrutura cultural osmotípica. Os elementos osmotípicos se originam das relaçóes culturais intertextuais, dos contatos entre culturas diferentes, dos processos sincréticos de elementos culturais de povos distintos, de valores, ritos, símbolos que provêm de universos culturais diferentes e que são reorganizados num cosmos no âmbito de uma cultura específica. As contribuiçóes de Stuart Hall são relevantes para que se compreenda a estrutura cultural osmotípica. É nesses sentidos que este estudo se refere aos elementos culturais arquetípicos, osmotípicos e lidertípicos. Por fim, foi essencial a contribuição de Cremilda Medina para compreender como ocorrem os processos de mediação de significados culturais intertextuais no ambiente social. Em essência, esses processos de mediação desencadeiam narrativas que os sujeitos fazem a respeito da realidade caótica, a fim de reoganizá-la num cosmos compreensível. Esses mesmos processos possibilitam a integração cultural e a reorganização das identidades culturais na fase contemporânea da globalização.

\section{Samuel Huntington - identidade cultural e civilização}

A identidade cultural é formada com diferentes elementos culturais que podem ter distintos significados intertextuais para cada indivíduo ou grupo social. São elementos culturais os valores sociais e os modos de pensar, os costumes e o estilo de vida, as instituiçôes, a história comum, os grupos étnicos, o meio ambiente natural e cultural, os pressupostos filosóficos subjacentes às relaçóes sociais e outros elementos a que certa sociedade atribui significados culturais intertextuais específicos. Com base em elementos como esses, o indivíduo e o grupo social formam a convicção de que compartilham uma cultura. Em graus mais amplos de generalização, a identidade cultural pode ser caracterizada a partir dos conceitos de nação e de civilização. Huntington faz a importante observação de que o nível mais amplo possível de identidade cultural é a civilização. Esse autor esclarece que a idéia de civilização foi desenvolvida no século XVIII por pensadores 
franceses, com o objetivo de contrapor a civilização ao conceito de sociedades "bárbaras", isto é, não civilizadas de acordo com os critérios adotados pelos próprios europeus. Nesse sentido, fala-se em civilização, no singular. Ser classificado como povo civilizado era bom, ser considerado um povo bárbaro era ruim. O conceito europeu de civilização estabeleceu critérios com base nos quais as sociedades poderiam ser julgadas e classificadas. Essa concepção era relevante porque, a partir dela, os europeus definiam quais eram as sociedades suficientemente "civilizadas" para integrar o sistema internacional dominado pela cultura européia. Apesar disso, Huntington observa que cada vez mais as pessoas falavam em "civilizaçóes", no plural. Isto levava a admitir que poderiam existir outros padróes de definição de civilização e, em conseqüência, exigia a renúncia à concepção de que a civilização européia era $\underline{o}$ ideal de civilização. Passou-se a admitir a existência de várias civilizaçóes, cada qual "civilizada" a partir de seus próprios critérios. Uma civilização, no sentido plural, poderia ser não-civilizada no sentido singular, europeu. Diz Huntington que a civilização (no sentido singular e no plural) é uma entidade cultural. Civilização e cultura estão relacionadas ao estilo de vida geral de um povo, porém a civilização é uma entidade cultural muito mais ampla e abrangente. Nesse sentido, nenhuma das unidades culturais abrangidas pela civilização pode ser pensada ou compreendida sem que se faça alguma referência à civilização que a abrange. Uma civilização tem longevidade cultural. Comparada a outros fenômenos históricos, uma civilização dura muito tempo. Huntington sustenta que, de todos os elementos culturais que caracterizam uma civilização, a religião é o mais importante porque transcende as fronteiras dos Estados e, muitas vezes, sobrevive a eles. Muitos Estados desapareceram sem que isto impedisse a manutenção e a expansão de identidade religiosa entre diversos povos. Os elementos de identificação cultural variam muito de uma sociedade para outra e Huntington entende que a revitalização da religiáo no mundo reforça as diferenças culturais. $\mathrm{O}$ autor diz que em larga medida as principais civilizaçóes da História da humanidade identificaram-se com grandes religióes. Povos de mesma etnia e idioma freqüentemente se massacraram uns aos outros por acreditarem em deuses diferentes. Aliás, a esse propósito, não se pode deixar de registrar aqui que a História pré-colonial da América é exemplo cabal dessa afirmação 
(CARDOSO, 1981). Huntington divide o mundo de acordo com as grandes civilizaçóes que identificou a partir do critério maior da religião. Essas grandes civilizaçôes são: a Ocidental, a Africana, a Islâmica, a Sínica, a Hindu, a Ortodoxa, a Latino-americana, a Budista e a Japonesa. Relaciona as características essenciais da civilização Ocidental: 1) recebeu grande legado clássico das civilizaçóes grega e romana; 2) adota o Cristianismo nas duas grandes vertentes do catolicismo e do protestantismo; 3) apresenta há séculos a separação da autoridade espiritual da autoridade temporal e suas respectivas instituiçóes; 4) adota o princípio da submissão de todos, inclusive do Estado, ao império da lei; 5) adota o pluralismo social; 6) em razão do pluralismo social, tem entidades e instituiçóes representativas dos diversos grupos sociais; 7) adota o princípio do individualismo, com a garantia de direitos e liberdades individuais. Esses aspectos da civilização ocidental são contextualizados por Huntington nestes termos (HUNTINGTON, 1997, p. 29):

A política mundial está sendo reconfigurada seguindo linhas culturais e civilizacionais. Nesse mundo, os conflitos mais abrangentes, importantes e perigosos não se darão entre classes sociais, ricos e pobres, ou entre grupos definidos em termos econômicos, mas sim entre povos pertencentes a diferentes identidades culturais. As guerras tribais e os conflitos étnicos irão ocorrer no seio das civilizaçôes. [...].

Essas ponderações de Huntington são adotadas neste estudo como um dos fundamentos para se analisar como os elementos de identificação cultural são produzidos, reproduzidos, transformados ou afirmados numa dada sociedade.

\section{Néstor Canclini e as estruturas culturais lidertípicas}

Canclini diz que o conceito antropológico de cultura é resultado paradoxal da expansão imperial do Ocidente. $\mathrm{O}$ autor faz a aguda observação: a Antropologia tradicional estudou a identidade cultural com base na premissa de que os membros de uma sociedade pertenceriam a uma só cultura homogênea, coerente, localizada num espaço determinado e distintiva das 
demais. Entretanto, o autor esclarece que em razão dos processos de expansão colonial liderado pelas potências eutopéias ocorreram contatos culturais intensos e profundos. A partir desse fenômeno, a Antropologia começou a realizar estudos mais voltados à interculturalidade CANCLINI, 2005). Os europeus mergulharam, então, em estudos a respeito da relativização do dogma de sua superioridade cultural. Tornou-se cada vez mais inconsistente a tendência de desqualificar as culturas e civilizações que, a partir de critérios europeus, eram consideradas "primitivas". Por isto, passou-se a considerar como cultura tudo aquilo que é produzido material ou idealmente pelo ser humano, não importando seu grau de complexidade e de desenvolvimento (EAGLETON, 2005), inclusive práticas que costumavam escandalizar os europeus, como a antropofagia, a poligamia, a nudez, os sacrifícios humanos. A lógica dessas formas de manifestação cultural começaram a ser analisadas no contexto das estruturas a que a pertenciam. Com fundamento nessa noção de estruturalismo cultural, passou-se à concepção do relativismo cultural, critério teórico com o qual, por um lado, se queria negar a existência de culturas "superiores" ou "inferiores" e, por outro, afirmar a existência de diferentes culturas. Canclini assinala que a concepçâo estruturalista da cultura contribuiu para a difusão do relativismo cultural e para descartar as qualificações evolucionistas da cultura e a classificação das culturas em "superiores" e "inferiores". Nesse sentido, relembra que os habitantes da América já tinham impressionante desenvolvimento cultural e civilizacional muito antes da chegada dos conquistadores europeus. Dominavam tecnologia avançada para seu tempo, alguns já tinham sistema de escrita e sofisticado sistema de contabilidade, realizaram obras de engenharia e arquitetura impressionantes, domesticaram muitos alimentos e animais, apresentavam complexa rede social e de organização política, inclusive com Estados bem caracterizados, dominavam técnicas de fabricação de cerâmica, artefatos em pedras preciosas e semipreciosas e ourivesaria. Era difícil ou inútil negar essas fantásticas contribuiçôes que os povos pré-colombianos deram à civilização européia desde a conquista e a colonização da América Latina. De modo geral, os estudos culturais europeus passaram a admitir que cada cultura se desenvolve de modo autônomo e que não há critérios teóricos aceitáveis para atribuir superioridade de uma civilização em face das demais. Todavia, o autor 
discorda em parte da concepção estruturalista e do conseqüente relativismo cultural adotados pela antropologia moderna. Admite que a concepção estruturalista e o relativismo cultural dela decorrente colaboraram para a superação dos dogmas etnocentristas, mas entende que não contribuíram para pensar e resolver os conflitos oriundos das diferenças interculturais. Assinala que a concepção estruturalista imagina que haveria uma série de cordóes sanitários entre as culturas, circunstância esta que impediria que dentro de uma mesma sociedade ou numa escala global as diferenças culturais fossem realmente trabalhadas e superadas. $\mathrm{O}$ autor sublinha que as culturas interagem umas com as outras. Além disso, ressalta que a assimetria de poder político, ideológico, econômico e cultural precisa ser levada em consideração quando se quer estudar a interdependência cultural, pois a produção e a reprodução das culturas dominantes ou hegemônicas são intrínsecas aos mecanismos da dominação capitalista. Propóe, então, outro conceito de cultura, mais abrangente e inserido na lógica de produção capitalista como um produto cultural, ao mesmo tempo em que acentua a função essencial da cultura como meio de produzir e de reproduzir os significados abrangidos nesse processo produtivo (CANCLINI, 2005, p. 30):

Por essas razóes, preferimos restringir o uso do termo cultura para a produção de fenômenos que contribuem, mediante a representação ou reelaboração simbólica das estruturas materiais, para a compreensão, reprodução ou transformação do sistema social, ou seja, a cultura diz respeito a todas as práticas e instituiçóes dedicadas à administração, renovação e reestruturação do sentido. [...].

Portanto, toda manifestação cultural deve ser estudada em conexão com os demais elementos produtivos do sistema social. Qualquer prática social é simultaneamente econômica e simbólica, pois é assim que se reproduz o conjunto de representaçóes de uma sociedade. A cultural, como processo produtivo específico, está conectada aos demais processos produtivos sociais e, para estudá-la, é preciso percorrer todas as etapas da produção cultural: a produção cultural propriamente dita, sua circulação, recepção e reprodução. Não é possível compreender o processo cultural desvinculado do sistema produtivo como um todo. Assim, a cultura é um dos instrumentos de 
dominação usados pelos países centrais, além do poder político e do econômico. Não é possível manter indefinidamente a dominação apenas com base na força militar, econômica ou política. Por isto, o elemento cultural, associado à manipulação ideológica, é imprescindível para assegurar a continuidade da dominação (CHAUí, 1980). A cultura contribui para que (i) os membros de um grupo aceitem certa estrutura de dominaçáo econômica e política como se fosse legítima e natural, ocultando a violência inerente ao processo de adaptaçáo do indivíduo a uma estrutura em cuja construção não interveio necessariamente; e (ii) faz com que a imposição da estrutura seja sentida como socialização ou adequação necessária para a vida em sociedade. Esta configuração exposta por Canclini constitui o que neste trabalho se denominou estrutura cultural lidertípica, em que os elementos de identificação cultural são apropriados, manipulados e difundidos pelos setores dominantes ou hegemônicos de um dado sistema social, de modo autoritário e hierarquizado, como se fossem legítimos elementos culturais para que os integrantes da sociedade construam sua identidade cultural. Nem todas essas ponderaçóes de Canclini são corretas, pois, como se verá adiante, os processos dialéticos culturais exigem a atuação contínua de agentes mediadores de significados intertextuais.

Os argumentos apresentados por Canclini constituem, neste estudo, mais um fundamento para se compreender como os elementos de identificação cultural são produzidos, reproduzidos, transformados ou afirmados numa dada sociedade.

\section{Stuart Hall e as estruturas culturais osmotípicas}

A identidade cultural é tema freqüente nos estudos atuais de teoria social. Identidades tradicionais, que prevaleceram durante muito tempo para certas sociedades, estão em processo de fragmentação na esfera individual e na social. Novas identidades culturais surgem e provocam a denominada "crise de identidade", que é parte de amplo e profundo movimento de transformação que desloca as estruturas de identidade cultural das sociedades modernas dos seus centros tradicionais de referência. Tornaram-se instáveis os critérios com base nos quais indivíduos e grupos sociais construíam sua identidade cultural (HALL, 2005). Em geral, as culturas existentes no mundo 
atual estão sendo cada vez mais descentradas, deslocadas e fragmentadas. As múltiplas dimensôes da globalização tornaram muito relativas as noções de tempo e de espaço. Núcleos culturais muito diferentes entre si, localizados em pontos do planeta distantes uns dos outros, hoje interagem de modo instantâneo por meio das telecomunicaçóes. No passado, contatos culturais entre povos diferentes progrediam lentamente, durante séculos, na medida em que se aperfeiçoaram os meios de transporte e de comunicação. Por isto, os diferentes povos tiveram tempo razoável para assimilar elementos culturais uns dos outros e para incorporar tais elementos em sua própria cultura, conforme se fazia necessário ou conveniente. Esse processo atualmente é muito mais intenso e, em termos relativos de tempo, é também instantâneo. Daí resultam os fenômenos da descentralização, deslocamento e fragmentação cultural a que todos se submetem na fase contemporânea da globalização. É interessante anotar que se tornou corriqueiro o uso do neologismo glocalização para expressar o contraste, a interação, a assimilação e o hibridismo do conjunto de fenômenos multidimensionais da globalização correlacionados com os fenômenos igualmente multifacetados de uma localidade e de um povo em particular.

Hall apresenta três concepçóes de identidade do sujeito: o sujeito do Iluminismo; o sujeito sociológico; e o sujeito pós-moderno. O sujeito do Iluminismo era concebido a partir de seu individualismo. Era indivíduo totalmente centrado, unificado e dotado de racionalidade para conduzir suas açôes no ambiente social. Sua identidade estava em seu interior e o acompanhava em toda a sua trajetória de vida. Por outro lado, o sujeito sociológico é resultado da crescente complexidade do mundo moderno, decorrente do aprofundamento histórico da Revolução Industrial, em que a construção da identidade individual não podia mais ser feita exclusivamente a partir dos critérios de identidade pessoal e subjetiva. Percebeu-se que a identidade de tal sujeito estava correlacionada com a identidade de outros indivíduos do corpo social, os quais desempenhavam papel de mediadores de valores, sentidos e símbolos para a construçâo da identidade cultural subjetiva. Hall ressalta que nessa concepção sociológica a identidade do sujeito é formada por sua interaçâo com o meio social. Embora o sujeito ainda mantenha um núcleo individual de identidade, sofre diversas influências de seu diálogo com os mundos culturais exteriores a ele, os quais 
desencadeiam um movimento de transformaçáo da identidade subjetiva, integrando-a à identidade social em constante mutação. $\mathrm{O}$ sujeito de algum modo organiza essas identidades culturais internas e externas e constrói um novo quadro de referência a respeito de seu lugar no mundo social e cultural. Usando uma feliz figura de linguagem, Hall diz que a identidade "costura" o sujeito à estrutura, dando-lhe estabilidade e possibilidade de predizer alguns dos movimentos culturais nos quais se integra. Todavia, na fase atual da globalização, especialmente a partir do final do século XX, a construção dessa identidade do sujeito sociológico também atravessa uma crise sem precedentes, fato que levou Hall a investigar a terceira forma de identidade cultural: a do sujeito pós-moderno. Explica que a identidade do sujeito sociológico está em crise porque, atualmente, o que está em processo de transformação é a própria estrutura exterior à qual a identidade interior do sujeito se ligava para construir seus quadros de referência. O sujeito antes tinha uma identidade unificada e estável, mas agora tem identidade fragmentada, muitas vezes contraditória e ainda não reorganizada. Nas sociedades atuais que atingiram grande complexidade e têm relaçôes multidimensionais inerentes à globalização, alguns elementos de identificação cultural, externos ao sujeito, transformam as estruturas e instituiçóes que serviam de referências para ele formasse sua própria identidade no meio social. Tudo passou a ser provisório, problemático e variável. Nessas circunstâncias tão instáveis, tem início a construção da identidade cultural do sujeito pós-moderno.

A crise de identidade provocada pela dinâmica da globalizaçáo cultural envolve profundo processo dialético. $\mathrm{O}$ indivíduo vivencia simultaneamente a influência de diferentes culturas que abalam a noçáo de identidade cultural "estável" com que ele estava habituado no contexto local em que se inseria. Desses choques culturais, ora decorre a complementaridade entre as culturas global e local; ora resulta uma situação circunstancial, transitória ou permanente, de hegemonia de uma cultura sobre a outra (ou seja, da cultura global sobre a local, ou vice-versa); ora advêm fraturas culturais com zonas de atrito ainda náo solucionadas (HUNTINGTON, 1981). Tratase de processo dialético complexo e profundo que torna necessário rever os critérios em que se baseiam a identificação cultural do indivíduo e da sociedade em que ele se insere. 
Por essas razóes, é oportuno tratar da questão mais específica da identidade nacional. A identidade cultural nacionalé uma das estruturas mais importantes desde o surgimento dos Estados nacionais europeus. A nacionalidade não é uma identificação genética, mas um sentimento profundo que o sujeito tem de "pertencer" a certa cultura nacional ou civilizacional. O indivíduo pensa nessas referências culturais como se elas efetivamente fizessem parte de sua essência. Hall esclarece que a identidade nacional é formada por meio de representaçóes que o sujeito faz a respeito do ambiente e da sociedade em que vive. $\mathrm{O}$ sujeito formula essas representaçóes e lhes atribui significados coerentes com os significados intertextuais adotados pela sociedade. A identidade nacional é, assim, um sistema de representaçôes culturais dotadas de significados intertextuais válidos e aceitos por determinado povo. A nação se apresenta como uma comunidade simbólica e é isto que gera o sentimento de identificação e de lealdade entre seus integrantes. $\mathrm{O}$ autor pondera que a noção e os fundamentos da identidade nacional são relativamente recentes na história humana. Os vínculos de lealdade e as formas de identificação social foram lenta, parcial e gradualmente transferidos da família para grupos sociais mais amplos, como o clá, a tribo, a comunidade regional, a comunidade religiosa e para a nação moderna. Nesse processo evolutivo, as eventuais diferenças culturais entre os indivíduos ou grupos subordinaram-se (não importa por quais motivos) aos elementos de identificação cultural mais amplos, como os da nação. O Estado-nação absorve elementos culturais que lhe interessam e, a partir de certo grau de generalização, atribui-lhes homogeneidade para com eles construir a identidade nacional. Note-se que Hall enxerga no Estadonação a comunidade cultural mais ampla, diferentemente de Huntington, que considera a civilização (definida em última análise pela identificação religiosa) como a mais ampla, abrangente e duradoura comunidade cultural. Hall sistematizou e organizou os elementos essenciais que servem de base à identificação cultural nacional, dividindo-os em cinco grupos (HALL, 2005). Primeiro, menciona que a identidade cultural é construída com base na narrativa a respeito da nação, isto é, nas histórias e nas literaturas nacionais, na mídia e na cultura popular. Esses elementos, considerados como conjunto de narrativas fornecem imagens, panoramas, cenários, eventos históricos, símbolos e rituais nacionais que simbolizam ou representam as experiências 
compartilhadas e que dão sentido à coesão da nação como comunidade "imaginada". A nação dá significado e importância à existência do indivíduo, na medida em que o conecta com objetivos nacionais que precedem sua existência e que provavelmente perdurarão depois de sua morte. Em segundo lugar, Hall refere-se à importância das origens, da tradição e da transcendência temporal como elementos de identificação cultural nacional. Ressalta que se constrói a convicção de que elementos essenciais do caráter nacional permanecem imutáveis, apesar de todas as variaçóes da história. O sentimento de identidade nacional é idealizado como primígeno, unificado e contínuo, eterno, “imutável” apesar das transformaçôes do mundo. Em terceiro lugar, o autor indica o uso das estruturas culturais lidertípicas para "construir" ou "inventar" a tradição que funcionará como elemento de identificação cultural. Os poderes dominantes ou hegemônicos concebem um conjunto de práticas, de representações simbólicas reais e ideais, e assim incutem nos indivíduos valores e normas de comportamento destinados a perpetuar um passado histórico "adequado" à construção de uma identidade nacional. Em quarto lugar, menciona que a identidade cultural nacional pode ser ancorada no chamado mito fundacional, isto é, numa estória que localiza a origem da nação, do povo e de seu caráter nacional num passado imemorial, mítico, desvinculado do tempo real. Trata-se aí das estruturas culturais arquetípicas, tão importantes na configuração e na construção da identidade cultural individual, social e nacional. Hall ressalta que os mitos fundacionais ajudam povos oprimidos ou marginalizados a expressar seu ressentimento e sua insatisfação em termos compreensíveis, na medida em que os mitos propóem uma história alternativa ou uma contra-narrativa em relação à história hegemônica. Finalmente, a identidade nacional muitas vezes diz que um povo é original, puro ou que tem certo atributo especial que o distingue de todos os demais. Interessante observar, aqui, que os atuais povos latino-americanos frequentemente recorrem aos mitos fundacionais para fazerem suas contra-narrativas culturais em oposição aos poderes dominantes a que estão sujeitos.

Uma nação é sempre composta por indivíduos e grupos que podem ser muito diferentes entre si. Apesar dessas diferenças, a partir de certo grau de generalização a cultura nacional congrega esses indivíduos e grupos em torno 
de uma identidade compartilhada, chamada identidade nacional ou mesmo civilizacional. Entretanto, como observa Hall, não se pode perder de vista o fato de que a cultura nacional é também uma estrutura de poder cultural. Ao longo da história da humanidade, a maior parte das naçóes foi unificada por meios violentos, ou seja, pela supressão de diferenças culturais pelos grupos ou povos dominadores em relação aos grupos ou povos dominados, de tal maneira que a cultura dominante se afirmou sobre as culturas submetidas. Sendo assim, a cultura dominante precisa construir uma estrutura de poder cultural destinada a fazer com que os grupos e povos submetidos "esqueçam" sua identidade cultural pretérita e, a seguir, adotem a nova identidade ditada pela estrutura cultural lidertípica. Cabe observar que nem sempre o poder cultural é exercido como poder ideológico. A ideologia, em essência, apresenta-se como um discurso com o objetivo de legitimar a dominação, tornando-a aceitável pelos sujeitos dominados (CHAUÍ, 1980). Há casos, porém, em que o poder cultural não recorre ao discurso ideológico para ser exercido. Por exemplo, muitas das comunidades indígenas andinas preservam tenazmente suas identidades culturais locais, apesar de estarem sujeitas à dominação cultural ocidental européia e norte-americana. Algumas recentes manifestações de auto-afirmação cultural na América Latina (Venezuela, Bolívia, México, Peru) têm procurado resgatar elementos culturais ancestrais e através desse processo fortalecer o sentimento de unidade do respectivo povo, contrapondo-se aos elementos culturais dominantes ou hegemônicos.

O progresso tecnológico, especialmente nas áreas de telecomunicaçóes e transportes, tende a eliminar a importância relativa do espaço e do tempo na dinâmica dos fenômenos globais. Ora, o espaço e o tempo sempre foram importantes coordenadas para validar e dar sentido aos sistemas de representaçóes culturais. Conforme essas coordenadas se tornam mais fluidas, os próprios sistemas de representação baseados nelas podem se tornar mais permeáveis a novas influências culturais: questôes culturais suscitadas em lugares distantes ou em tempos diferentes podem tornar-se questôes atuais e locais para individuos e sociedades que, em principio, estariam temporal e fisicamente apartados daquelas questóes. A sensação de que tudo acontece aqui e agora faz com que fenômenos culturais globais possam ter significação simbólica local, transformando os paradigmas de identificação cultural até então vigentes. 
Por outro lado, as culturas locais dispóem de mecanismos internos mais ou menos eficientes para não se desintegrarem totalmente. Isto faz parte do processo dialético de auto-afirmação cultural já referido. É curioso - e é mesmo paradoxal - observar que o processo global de integração cultural, que tende a fazer aquilo que chamo (parafraseando Marx) de gelatina cultural, é o mesmo que acentua as diferenças culturais. As pessoas vão a diferentes lugares, compram diferentes roupas, comem diferentes comidas, assistem a diferentes espetáculos, professam diferentes religióes exatamente por causa das diferenças que percebem em cada uma dessas situaçôes. A busca da diversidade em seu mais amplo sentido e, em especial, a diversidade cultural, é essencial no ser humano. Trata-se de um processo que envolve a alteridade global-local para construir, reconstruir, transformar, diluir ou miscigenar a identidade cultural do indivíduo e da própria sociedade em que ele se insere, sociedade esta que tem hoje escala planetária.

O processo de globalização é assimétrico, desequilibrado, assincrônico e heterogêneo. Nem todas as partes do mundo estão inseridas nesse processo de modo uniforme e simultâneo (DUPAS, 2005). A globalização torna cada vez mais relativa a idéia clássica de sociedade como um corpo bem definido e delimitado, dotado de mecanismos internos e externos muito claros para permitir que seus integrantes se identifiquem com uma certa cultura. $\mathrm{O}$ processo dialético de auto-afirmação das diferentes culturas apresenta três efeitos importantes, de certo modo contraditórios, destacados por Hall: 1o) as identidades culturais locais estão ameaçadas de desintegração provocada pelo crescimento da homogeneização cultural globalizada; $2^{\circ}$ ) as identidades nacionais e locais realizam importante esforço de resistência à globalização cultural, buscando sua auto-afirmação; e $3^{\circ}$ ) é fato que as identidades nacionais e locais absorvem novos elementos culturais e estão se tornando culturas híbridas. A análise de Hall evidencia a profunda influência das estruturas culturais osmotípicas na construção e reprodução da identidade cultural do indivíduo, do seu grupo social mais restrito, de sua nação e de sua civilização, no mundo contemporâneo. $\mathrm{O}$ processo de fragmentação cultural analisado exige que alguns critérios de identificação cultural sejam abandonados, outros sejam assimilados, outros sejam harmonizados, de maneira a gerar um novo universo referencial dentro do qual a identidade cultural se expressará. 
Os movimentos de mutação do indivíduo, da sociedade em que ele vive e das próprias estruturas e instituições no mundo globalizado determinam, por um lado, a inafastável interação cultural, verdadeira osmose cultural, que resulta em culturas híbridas formadas com elementos de identificação cultural provenientes de todas as partes do mundo; por outro lado, os mesmos movimentos de transformação desencadeiam processo dialético muito mais intenso, em que se contrapóem as culturas locais e as não locais (sejam estas hegemônicas ou não), numa luta simbólica em que cada cultura quer se afirmar perante as demais.

Huntignton discorda da afirmação de que o processo de globalização e, em especial, a mídia, estejam conduzindo necessariamente a uma homogeneização cultural. Esse autor faz a importantíssima observação de que o entretenimento cultural não equivale à conversão cultural. Acentua que na intensificação da globalização ocorre uma exacerbação da autoconsciência civilizacional, societária e étnica. Daí porque não acredita na hegemonia de uma cultura ocidental universal (HUNTINGTON, 1997, p. 111):

Através da História, a expansão do poder de uma civilização geralmente ocorreu ao mesmo tempo que o florescimento da sua cultura e quase sempre requereu dela usar seu poder para estender seus valores, práticas e instituiçôes a outras sociedades. Uma civilização universal requer um poder universal. [...]. O colonialismo europeu terminou; a hegemonia norte-americana está retrocedendo. Segue-se a erosão da cultura ocidental, enquanto se reafirmam costumes, idiomas, crenças e instituiçôes indígenas com raízes históricas. $\mathrm{O}$ crescente poder das sociedades não-ocidentais produzido pela modernização está gerando um renascimento das culturas não-ocidentais pelo mundo afora.

Para Huntington, a pretensão ocidental de ter uma cultura hegemônica e universal não é factível. Pondera que nas fases iniciais de integração multidimensional provocada pela globalização, a modernidade ocidental era atrativo para as culturas não tão modernas. Posteriormente e na medida em que a modernização aumentou o poderio econômico, político e militar dos povos antes submetidos à dominação ou à hegemonia ocidental, observouse rejeição intensa da cultura ocidental e uma correlata auto-afirmação 
cultural, local ou regional, de civilizaçôes dissidentes em relação ao ocidente. $\mathrm{O}$ aumento do poderio econômico, militar e político da sociedade como um todo, decorrente da modernizaçáo, incentiva as pessoas dessas sociedades não ocidentais a terem confiança na sua própria cultura. No que concerne à identidade cultural individual, a modernização gera sentimentos de crise de identidade, decorrente da fragmentação cultural sofrida pelo sujeito à medida que laços tradicionais e relações sociais são rompidos. Nessa situação, o indivíduo tende a buscar na religião uma resposta para esses conflitos. Está aí, segundo Huntington, uma das causas essenciais do renascimento religioso mundial, que torna a religiáo o mais amplo e abrangente critério de identificação cultural. No âmbito do processo multidimensional de globalização do mundo moderno, há uma tendência individual, coletiva e social de afirmar e reafirmar sua identidade cultural em termos civilizacionais. $\mathrm{Na}$ medida em que se aceite a proposição de Huntington de que a religião é o critério mais importante para caracterizar uma civilização (e esta proposição é aceita neste trabalho), não se pode deixar de aceitar, como conseqüência, que as estruturas culturais arquetípicas são importantíssimas para a identificação cultural. Todas as religióes fundamentam-se em estruturas culturais arquetípicas, em especial nos mitos e simbolismos religiosos. É necessário, então, examinar essas estruturas. Para essa tarefa, a contribuição de Mircea Eliade é essencial.

\section{Mircea Eliade e as estruturas culturais arquetípicas}

Mircea Eliade esclarece que apenas no decorrer do século XX tomou-se consciência de que o símbolo, o mito e a imagem pertencem à substância da vida espiritual. Mesmo que se tente minimizar sua importância, escondêlos ou mutilá-los, não se pode retirá-los jamais da essência humana. O pensamento simbólico é intrínseco ao ser humano porque precede a linguagem e a razão discursiva. Revela os mais profundos aspectos da realidade que desafiam qualquer outra forma de conhecimento humano e que não podem ser expressos noutra linguagem. O pensamento simbólico cumpre, portanto, a função de revelar as profundezas essenciais do ser humano. Eliade diz que exatamente por isto o pensamento simbólico permite conhecer melhor o homem naqueles aspectos em que o indivíduo ainda não se compôs com a 
história.

Por meio do pensamento simbólico, qualquer ser humano pode explorar os significados que vêm de seu inconsciente. Eliade assevera que o "inconsciente", é muito mais "poético", mais "filosófico", mais "mítico" que a vida consciente, pois contém os monstros e as divindades, os heróis e as fadas que continuam a preencher as mesmas funçóes que tiveram em todas as mitologias: ajudar o homem a libertar-se. As imagens e o pensamento simbólico são, por suas próprias estruturas, multivalentes. Surgem na mente humana como instrumentos de captação e expressão da realidade profunda das coisas, que pode ser bastante contraditória e, por isto mesmo, irredutível à expressão por meio de conceitos racionais. Desse modo, a linguagem e o próprio pensamento simbólico são verdadeiros enquanto conjunto de significados reveladores da realidade essencial, não se podendo adotar significado único para expressar aquela realidade. Por esses motivos, qualquer ser humano, do mais simples ao mais realista, inexoravelmente, convive com as suas imagens e pensamentos simbólicos para compreender a si próprio e o mundo em que vive.

A aptidão do ser humano de imaginar está imersa em pleno simbolismo e continua a recorrer aos mitos e às concepções religiosas mais arcaicas. A imaginação permite ao ser humano fruir de um fluxo ininterrupto e espontâneo de imagens que, contudo, não são imagens arbitrárias, pois elas "representam", imitam modelos exemplares arquetípicos, que podem ser reproduzidos infinitamente. As imagens permitem ao ser humano enxergar o mundo em sua totalidade porque elas têm o poder e a função de expressar o que não pode ser expresso em conceitos racionais. Os símbolos e imagens arquetípicos não são criações arbitrárias localizadas e privativas de algum ser humano primitivo. Ao contrário, originaram-se no interior de complexos culturais de certas sociedades humanas e foram difundidos e assimilados em pontos muito distantes de seu núcleo original. Isto põe em relevo seu caráter transcendente de tempo e de espaço. Revivendo imagens, mitos e símbolos arquetípicos, o ser humano ultrapassa seu lugar e seu momento histórico e se realiza como ser integral e universal, pois compreende melhor seu destino e sua significação. No plano racional, o ser humano expressa seus arquétipos por meio da narrativa dos mitos e imagens que vêm de seu pensamento simbólico. 
É por meio da narrativa que os significados arquetípicos são difundidos nos grupos sociais e contribuem para que o ser humano transcenda seu tempo e seu espaço. A esse propósito, Eliade esclarece que (1991, p. 174):

[...] a narração de um mito não é sem conseqüência para aquele que o recita ou para aqueles que o ouvem. Pelo simples fato da narração de um mito, o tempo profano é - pelo menos simbolicamente - abolido; narrador e auditório são projetados num tempo sagrado e mítico. [...] um mito retira o homem de seu próprio tempo, de seu tempo individual, cronológico, "histórico" - e o projeta, pelo menos simbolicamente, no Grande Tempo, num instante paradoxal que não pode ser medido por não ser constituído por uma duração. [...].

As imagens e símbolos arquetípicos, embora perenes e universais, são vivenciados e valorizados de modos diferenciados em cada grupo social e, por essa razão, são importantes elementos de identificação cultural (ELIADE, 2004). A perenidade e a universalidade dos arquétipos asseguram a consistência intrínseca das diversas culturas. Ao mesmo tempo, possibilitam fazer uma filosofia das culturas sem cair na vala das categorizaçóes morfológicas de estilos culturais. Analisar os fenômenos culturais exclusivamente sob os condicionamentos históricos é realizar abordagem muito limitada da cultura, segundo Eliade. $\mathrm{O}$ que é culturalmente importante para um europeu pode não ter a mínima importância para um asiático. Em contrapartida, imagens e símbolos arquetípicos precedem os condicionamentos históricos e, na maioria das vezes, informam esses condicionamentos, de modo que tais imagens e símbolos são universalmente acessíveis a qualquer ser humano, independentemente dos valores localizados que possam ter.

Por esssas razóes, as proposiçóes teóricas de Eliade são também adotadas neste trabalho como fundamentais para o estudo da identidade cultural em geral, e da identidade cultural latino-americana em particular. 


\section{Cremilda Medina e a mediação simbólica dos conflitos culturais contemporâneos}

Cremilda Medina contribui de modo essencial para a reflexão atinente às identidades culturais e aos relacionamentos multidimensionais entre culturas diferentes na fase contemporânea da globalização. A abordagem de Medina envolve o que Edgar Morin denominou "pensamento complexo", que combina a razão com as percepçóes intuitivas e com as manifestaçóes emocionais do ser humano, elementos estes enfeixados de maneira a possibilitar a mais ampla expressão da inteligência, bem como maior percepção e compreensão do mundo. Baseada em estudos precedentes de Jean Lohisse, cujo pensamento introduziu no Brasil, a abordagem de Medina póe em relevo o papel do sujeito como mediador dos significados culturais intertextuais da realidade e da sociedade em que se insere, de modo a ser, simultaneamente, por um lado, sujeito observador dessa realidade e, por outro lado, partícipe e construtor da mesma realidade que observa. Nesse contexto, tal sujeito necessariamente compartilha - e se solidariza com - os fenômenos da realidade que observa, compreendendo-a mais profundamente, decodificando e mediando os signos dessas relaçóes humanas. Em especial, Medina evidencia muito bem alguns dos aspectos mais importantes da interação entre as estruturas culturais lidertípicas e o sujeito que atua como mediador dos significados culturais intertextuais abrangidos nessa relação. A autora insiste em que a construção social dos sentidos acontece na rua, no cotidiano das pessoas, essencialmente por meio da narrativa oral, que chama de oratura, em contraste com a literatura. As intersecçóes possíveis entre literatura e oratura dão origem a uma produção intertextual, de que o narrador é ao mesmo tempo autor e personagem que media e compartilha os significados de sua produção com o resto da comunidade. Esse sujeito expressa na sua narrativa o pensamento simbólico referido por Eliade, bem como os diferentes elementos culturais fragmentados que interagem na vida cotidiana (às vezes de modo tão conflitante). Tal narrador reorganiza todos esses elementos, dá a eles significação própria no contexto social em que acontecem as relaçóes e assim, intervém e transforma sua realidade. Destaca esses aspectos como segue (MEDINA, 2003, p. 77): 
Um mediador-autor constrói uma narrativa contemporânea que ultrapassa a função disciplinada nas sociedades industriais e pósindustriais. Justamente autor, porque a identidade lhe dá o diferencial. Por sua vez, a marca de autor denuncia a identidade cultural: aquele autor só poderia surgir daquele grupo humano que se expressa numa textualidade registrada - a literatura - e numa textualidade da rua, do cotidiano, que atinge a grandeza da oratura. [...]. Nas zonas obscuras da intertextualidade coletiva que acontece fora dos limites da consciência, sem as regras da racionalidade, o poeta do momento recolhe sentidos profundos, o recado que vem do íntimo do ser.

Medina ressalta aspectos relevantíssimos a respeito da atuação dos mediadores dos significados culturais intertextuais, inteiramente pertinentes para a realização deste estudo. A narrativa é essencial para atribuir significação ao cotidiano social porque é uma resposta humana à angústia provocada pelo caos. A inteligência humana é dotada da capacidade de produzir significados durante a narrativa da realidade e, assim, consegue transformar o caos em cosmos. Em aguda observação, Medina diz que a narrativa da realidade constitui uma outra realidade, a realidade simbólica. É por meio da narrativa que o sujeito expressa sua humanidade, afirma a si próprio e responde à desorganização da vida. A narrativa é, assim, necessidade essencial do ser humano porque possibilita que ele interfira na sua realidade e se emancipe em todos os sentidos. $\mathrm{O}$ ato de narrar dá espaço a insights criativos, requer a manifestaçáo de afeto e o exercício da intuiçáo, que entáo o narradorautor organiza de forma racional, inteligível e dotada de significação. Por meio da narrativa da realidade que, como visto, passa a constituir uma outra realidade, a fragmentação cultural do indivíduo e da sociedade é reorganizada num cosmos dinâmico, em que as atitudes integradora e transformadora do ser humano encontram livre expressão. Isto exige que o narrador-autorpersonagem da realidade domine o conhecimento técnico-científico que lhe é útil para organizar e racionalizar sua narrativa, e também que tenha desenvolvido sua inteligência emocional e intuitiva a ponto de poder captar e mediar os significados culturais intertextuais das relaçóes sociais de que participa. O narrador-autor-personagem capta, atribui significação cultural e expressa os desejos anônimos dispersos no inconsciente coletivo, e no 
seu próprio inconsciente, compartilhando-os com os demais personagens da sociedade. Nesse processo, inexoravelmente o mediador de significados culturais intertextuais recorre aos arquétipos, confronta os lidertipos e concilia os osmotipos.

O processo dialético entre culturas locais e não-locais (sejam hegemônicas ou não), envolve sempre a atuação interventiva e transformadora de mediadores de significados culturais intertextuais em cada sociedade. As sociedades contemporâneas dependem cada vez mais de agentes sensíveis e capacitados para mediar grupos, comunidades e indivíduos integrados à rede de comunicação social, quaisquer que sejam os instrumentos para a realização dessa comunicação. Através da atuação e das narrativas desses mediadores de significados culturais intertextuais, as estruturas culturais lidertípicas, osmotípicas e arquetípicas saem do caos e são conciliadas e organizadas num cosmos. Essas narrativas são poderoso instrumento para lidar com a fragmentação das identidades culturais e dar significação às relaçôes entre culturas distintas na fase atual da globalização.

\section{Considerações sobre a identidade cultural latino-americana}

A formação de uma identidade cultural pressupóe, necessariamente, a alteridade e a diferença. Exige o reconhecimento da existência do outro e a aceitação de que o outro é diferente. Os elementos culturais caracterizadores de diferenças entre dois ou mais sujeitos, ou grupos, formam suas respectivas identidades culturais. Um sujeito ou grupo sabe quem é na medida em que consegue perceber quem não é, ou seja, quando não adota os mesmos elementos de identificação cultural que o outro adota, ou quando atribui a certos elementos culturais significados diferentes dos significados adotados pelo outro para os mesmos elementos. Quanto mais universalizantes forem os elementos de identificação cultural e seus respectivos significados, maior será o número de indivíduos e grupos que compartilharão a mesma identidade cultural. Na hipótese inversa, será menor o grau de identificação cultural dos indivíduos ou grupos. Não existe uma só identidade cultural para um indivíduo ou grupo social. Há vários graus e dimensóes possíveis de identificação cultural, mais amplos ou mais restritos. $\mathrm{O}$ mesmo indivíduo ou grupo social pode ter várias e diferentes identidades culturais conforme o grau 
de generalização ou universalização dos elementos e significados culturais adotados em cada caso. É preciso ter em mente esses aspectos quando se indaga sobre a possível existência de uma identidade cultural genuinamente latino-americana. A identidade cultural da América Latina como um todo poderá existir a partir de certo grau de generalização dos elementos gerais ou particulares de identificação cultural que a caracterizariam. Os diferentes grupos sociais que compóem a população latino-americana adotam elementos culturais mais restritivos, particulares, muito específicos, para formarem suas respectivas identidades culturais locais. É assim - afirmando suas diferenças - que caracterizam sua alteridade em face dos demais grupos sociais. Esses grupos sociais estabelecem entre si relaçóes multidimensionais e por isto podem introduzir e assimilar nas respectivas culturas locais vários outros elementos de identificação cultural geral, de modo que, nesses aspectos, os grupos se reorganizam. Todavia, em relação a outros grupos com os quais não compartilhem elementos de identificação cultural, preservam suas diferenças e seu sentimento de alteridade. Esses processos de formação, transformação e afirmação de identidades culturais tendem a oscilar entre a universalização crescente e a preservação tenaz das identidades locais. A identidade cultural latino-americana está inserida nesses processos. $\mathrm{O}$ movimento universalizante conduz à formação de identidades regionais, nacionais, civilizacionais, globais. Nessas circunstâncias, os elementos gerais de identificação da cultura ocidental dominante ou hegemônica coexistem com os de identidade cultural local da América Latina. Por outro lado, as identidades culturais locais latino-americanas também se expressam e reafirmam no ambiente global, continental, nacional e regional. Para esse fim, cada cultura local rejeita e exclui de seu universo cultural certos elementos culturais alienígenas, preservando seu sentimento de alteridade e de distinção em relação a outros grupos ou culturas. Desenvolve-se um processo dialético entre culturas diferentes, relacionadas entre si, cada qual pretendendo reconhecimento e afirmação em face das demais. Nesse processo há contínua intervenção dos mediadores de significados culturais intertextuais, porque esses agentes são, simultaneamente, observadores, partícipes e construtores dessa realidade,. Cada mediador de significados culturais intertextuais, como narrador-autorpersonagem da realidade, usa sua inteligência complexa para captar e mediar 
os significados das relaçóes sociais de que participa e intervir nasua realidade. Por meio das narrativas que faz sobre a realidade caótica, reorganiza-a num cosmos apreensível e compreensível pelos grupos sociais em que se insere e, desse modo, cria uma outra realidade, mais harmônica, justa, solidária. A reconstrução da identidade cultural da América Latina insere-se nesse contexto. Os povos latino-americanos estão expostos à circulação de elementos e significados culturais intertextuais. Os choques culturais serão inevitáveis e estarão sujeitos à ação dos agentes mediadores de significados culturais intertextuais. A narrativa da realidade feita por esses agentes constitui uma outra realidade - a simbólica - por meio da qual reorganizam e dáo sentido aos elementos culturais arquetípicos, lidertípicos e osmotípicos com que reconstruirão sua própria identidade cultural e a de seu grupo social. 


\section{Referências Bibliográficas}

ARANTES, Antônio Augusto. O que é cultura popular. 3. ed. São Paulo: Brasiliense, 1981.

BELLOTTO, Manoel Lelo; CORRÊA, Anna Maria Martinez. (Org.). A América Latina de colonização espanhola. 2. ed. São Paulo: Hucitec, 1991.

CANCLINI, Néstor García. Culturas híbridas. São Paulo: Escuta, 1991. . As culturas populares no capitalismo. São Paulo: Brasiliense. . Consumidores e cidadãos. 5. ed. Rio de Janeiro: UFRJ, 2005.

CARDOSO, Ciro Flamarion S. América pré-colombiana. 7. ed. São Paulo: Brasiliense, 1981.

CHAUÍ, Marilena. O que é ideologia. São Paulo: Brasiliense, 1980.

CHESNAYS, François. A mundialização do capital. São Paulo: Xamã, 1996.

CRUZ, Maria Tereza. A estética da recepção e a crítica da razão impura. Revista de Comunicação e Linguagens, Lisboa, n. 3, p. 57-67, jun. 1986.

DUPAS, Gilberto. Atores e poderes na nova ordem global: assimetrias, instabilidades e imperativos de legitimação. São Paulo: Unesp, 2005.

EAGLETON, Terry. A idéia de cultura. São Paulo: Unesp, 2005.

ELIADE, Mircea. Imagens e símbolos. São Paulo: Martins Fontes, 1991. . Mito e realidade. 6. ed. São Paulo: Perspectiva, 2004.

HALL, Stuart. A identidade cultural na pós-modernidade. 10. ed. Rio de Janeiro: DP\&A, 2005.

HARRISON, Lawrence E.; HUNTINGTON, Samuel P. A cultura importa: os valores que definem o progresso humano. Rio de Janeiro: Record, 2002.

HUNTINGTON, Samuel P. O choque de civilizaçóes e a recomposição da ordem mundial. Rio de Janeiro: Objetiva, 1997.

. Political order in changing societies. Cambridge: Harvard University Press, 1981. 
LAVINAS, Lena; CARLEIAL, Liana Maria da Frota; NABUCO, Maria Regina (Org.). Integração, regiāo e regionalismo. Rio de Janeiro: Finep, 1994.

MEDINA, Cremilda. A arte de tecer o presente: narrativa e cotidiano. São Paulo: Summus, 2003.

- Notícia, um produto à venda: jornalismo na sociedade urbana e industrial. 5. ed. São Paulo: Summus, 1988.

Povo e personagem. Canoas: Ed. Ulbra, 1996.

MELLO, Leonel Itaussú de Almeida. Argentina e Brasil: a balança de poder no cone sul. São Paulo: Annablume, 1996.

MERTON, Robert K. Social theory and social structure. New York: Free Press, 1968.

MORIN, Edgar. Introdução ao pensamento complexo. Porto Alegre: Sulina, 2005.

ROMANO, Ruggiero. Mecanismos da conquista colonial. 2. ed. São Paulo: Perspectiva, 1989. 